\title{
Characterization of odorants in adhesives
}

Charakterisierung von Geruchsstoffen in Klebstoffen

\author{
Der Naturwissenschaftlichen Fakultät \\ der Friedrich-Alexander-Universität Erlangen-Nürnberg \\ zur
}

Erlangung des Doktorgrades Dr. rer. nat

vorgelegt von

Philipp Denk 
Als Dissertation genehmigt von der Naturwissen-

schaftlichen Fakultät der Friedrich-Alexander-Universität

Erlangen-Nürnberg

Tag der mündlichen Prüfung: 05. November 2019

Vorsitzender des Promotionsorgans: $\quad$ Prof. Dr. Georg Kreimer

Gutachter/in: $\quad$ Prof. Dr. Andrea Büttner

Prof. Dr. Michael Rychlik 


\section{Table of contents}

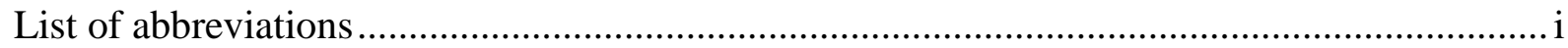

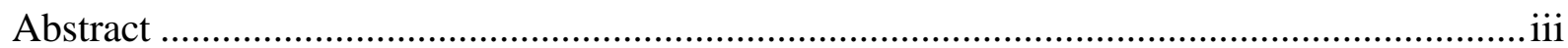

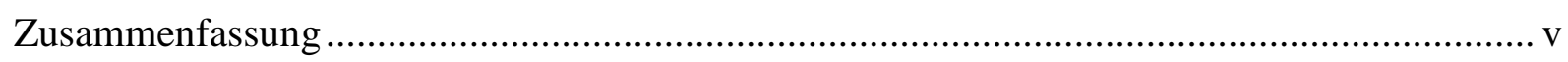

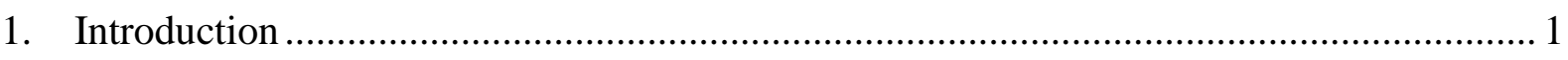

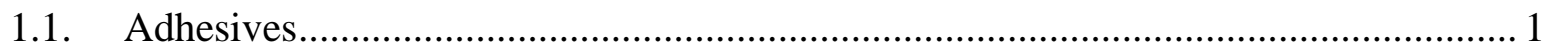

1.1.1. Historical development of adhesives............................................................ 1

1.1.2. Types of adhesives and their classification .................................................... 2

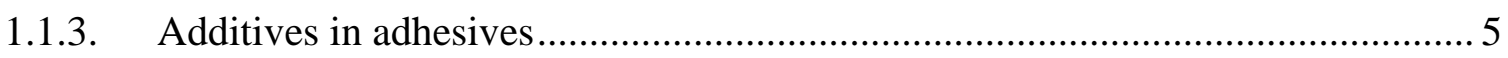

1.1.4. Mechanisms of adhesion ............................................................................ 7

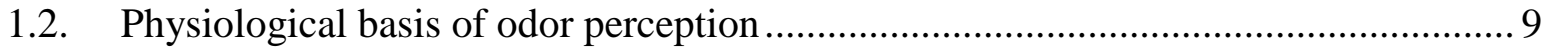

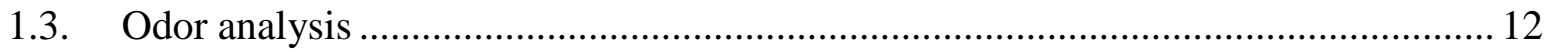

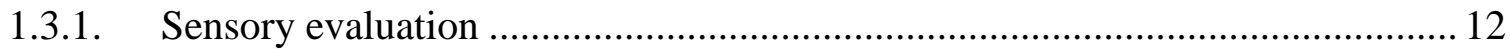

1.3.2. Isolation and sampling methods for volatile compounds ............................... 13

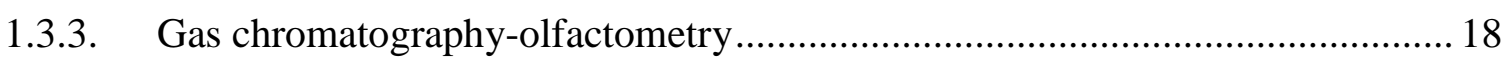

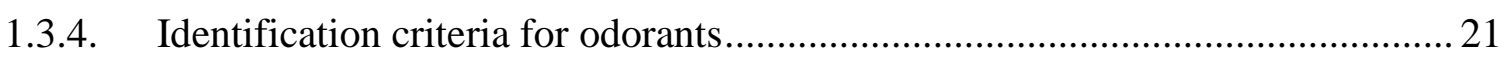

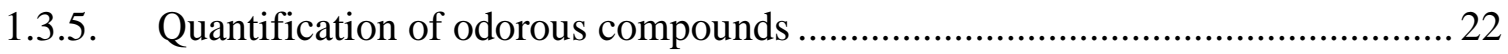

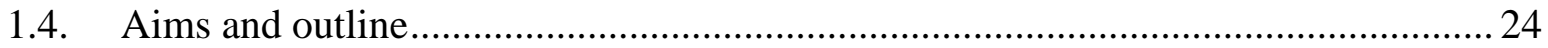

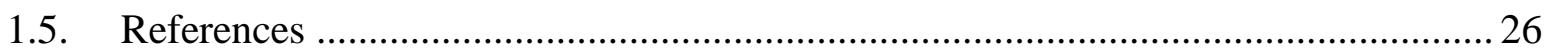

2. Sensory characterization and identification of odorous constituents in acrylic

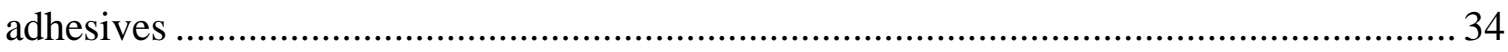

3. Identification and quantification of glue-like off-odors in elastic therapeutic tapes......... 35

4. Characterization of odorants in waxes for hot melt adhesives using sensory and

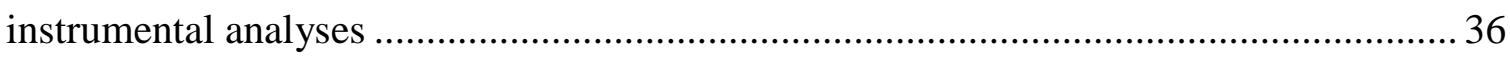

5. Correlations between odour activity and structural modifications of acrylates ................ 37 


\section{List of abbreviations}

2D-GC-MS/O Two-dimensional gas chromatography mass spectrometry/olfactometry

$\mathrm{AC}$

Adenylate cyclase

AEDA

Aroma extract dilution analysis

ATP

Adenosine triphosphate

cAMP

Cyclic adenosine monophosphate

DB-5

Durabond-5 ((5 \%-Phenyl-)methylpolysiloxane)

DB-FFAP

Durabond-Free fatty acids and phenols (polyethylene glycol modified with nitroterephthalic acid)

DCM Dichloromethane

FD

Flavor dilution

FID

Flame ionization detector

GC

Gas chromatography

GC-MS

Gas chromatography-mass spectrometry

GC-O

Gas chromatography-olfactometry

GPCR

G-protein coupled receptor

$\mathrm{mL}$

Millilitre

MS

Mass spectrometry

$m / z$

Mass to charge ratio

NIF

Nasal impact frequency

NIST

National Institute of Standards and Technology

NMR

Nuclear magnetic resonance

$\mathrm{O}$

Olfactometry

OAV

Odor activity value 
OB

OBS

OD

ODP

OE

OEDA

ONS

OR

PDMS

SNIF

RI

Rt

SAFE

SBSE

SPME

TDU

TIC

TRP

VOC

$\mathrm{v} / \mathrm{v}$

$\mu \mathrm{L}$
Olfactory bulb

Odorant binding protein

Odor dilution

Odor detection port

Olfactory epithelium

Odor extract dilution analysis

Olfactory sensory neuron

Olfactory receptor

Polydimethylsiloxane

Surface of nasal impact frequency

Retention index

Retention time

Solvent assisted flavour evaporation

Stir bar sorptive extraction

Solid phase micro extraction

Thermo desorption unit

Total ion count

Transient receptor potential

Volatile organic compound

Volume + volume

Microlitre 


\begin{abstract}
Adhesives are an indispensable material for joining different materials. Without adhesives, modern industry would not be able to produce such a large number of products. Adhesives are mostly synthetic, however natural ones, such as resins or casein, are also used. Since adhesives are often associated with unpleasant odors and little is known about the odorcausing compounds, this work deals with the elucidation of the odorants in adhesives.

In the first study, various acrylate-based adhesives were screened for odor active substances by means of gas chromatography-olfactometry (GC-O) and their identification by gas chromatography-mass spectrometry/olfactometry (GC-MS/O). In this way, a variety of odorants could be elucidated, which have previously not been reported in the literature as odor-active substances in adhesives. Besides odorous monomers associated with the adhesives, additional trace components with potent smell properties could be identified as odor causing substances.
\end{abstract}

In the second part of this work, four elastic therapeutic tapes, which were marked by a pronounced off-odor, were examined. These tapes contained an acrylic adhesive for the adhesion to the skin. Based on a series of GC analyses, more than 30 odor-active substances could be identified. Here, 2-ethyl-1-hexanol could be elucidated as one of the most potent odorants responsible for the off-odor. This substance is well-known as a degradation product of a monomer of acrylic adhesives. To put the relative smell contribution of these substances into relation to each other, 2-ethyl-1-hexanol and a series of other substances were quantified.

In the third part of the work, waxes with different manufacturing processes were investigated, due to the fact that hot-melt adhesives contain a large amount of synthetic waxes and play an important economic role in the field of adhesive manufacturing. In this case, different analytical approaches were administered, namely a solvent extraction as well as a thermal desorption of the odorous fraction followed by GC-MS/O analysis. In this way, a release of the odorants during the melting of an adhesive could be simulated. In addition to the odorants identified by solvent extraction, it was also possible to identify more highly volatile substances. This thermal desorption showed to be a fast and effective method for the identification of odors emanating during a melting process.

Acrylate-based products such as adhesives or paints have different compositions, potentially leading to a multitude of by-products, namely acrylate derivatives. As studies on real samples indicated a series of such by-products, different esters of acrylic acid were systematically 
synthesized and examined with regard to their odor properties, such as smell character and odor thresholds in the fourth part of this work. In addition, chromatographic and spectrometric data were compiled. Structural analogues containing acrylate moieties were found to exhibit olfactory similarities with known odorants lacking this specific structural feature. This allows elaborating structural features that are representative for specific smell impressions. Moreover, such data support future identification of unknown compounds. 


\section{Zusammenfassung}

Klebstoffe stellen in der heutigen Zeit einen unabdingbaren Werkstoff für das Fügen unterschiedlicher Materialien dar. Ohne diese wäre die moderne Industrie nicht in der Lage eine Vielzahl ihrer Produkte zu erzeugen. Bei den verwendeten Klebstoffen handelt es sich zumeist um synthetisch hergestellt Produkte, wobei auch natürliche Rohstoffe, wie beispielsweise Harze oder Casein, zum Einsatz kommen. Da Klebstoffe häufig mit einem unangenehmen Geruch verbunden sind und wenig über die geruchsverursachenden Verbindungen bekannt ist, befasste sich diese Arbeit mit der Aufklärung der in Klebstoffen enthaltenen Geruchsstoffe.

In einer ersten Studie wurden verschiedene Acrylat-basierte Klebstoffe einem Screening auf geruchsaktive Substanzen mittels Gaschromatographie-Olfaktometrie (GC-O) unterzogen, sowie deren Identifizierung durch Gaschromatographie-Massenspektrometrie/Olfaktometrie (GC-MS/O) durchgeführt. Auf diese Weise konnte eine Vielzahl von Geruchsstoffen aufgeklärt werden, welche in der Literatur noch nicht als geruchsaktive Substanzen in Klebstoffen bekannt waren. Neben geruchspotenten Monomeren der Klebstoffe konnten insbesondere Spurenkomponenten als geruchsverursachend aufgeklärt werden.

Im zweiten Teil dieser Arbeit wurden vier durch einen Fehlgeruch auffällige, kinesiologische Tapes untersucht. Diese enthielten für die Haftung auf der Haut einen Acrylatklebstoff. Mittels verschiedenen gaschromatographisch-olfaktometrischen Analysen konnten über 30 geruchsaktive Substanzen identifiziert werden. Hierbei wurde 2-Ethyl-1-hexanol als einer der potentesten Geruchsstoffe, ursächlich für den Fehlgeruch, aufgeklärt. Diese Substanz war bereits als Abbauprodukt eines Monomers von Acrylatklebstoffen bekannt und wurde zur Objektivierung ihres Beitrags, neben anderen Geruchsstoffen, einer Quantifizierung unterzogen.

Im dritten Teil der Arbeit wurden verschieden hergestellte Wachse untersucht, da HotmeltKlebstoffe einen großen Anteil an synthetischen Wachsen enthalten und somit als Basisrohstoffe im Bereich klebender Komponenten von hoher wirtschaftlicher Bedeutung sind. Hierbei wurde, neben einer Lösungsmittelextraktion, eine Thermodesorption mit anschließender GC-MS/O Analyse durchgeführt. Auf diese Weise konnte eine Freisetzung der Geruchsstoffe während des Schmelzens eines Klebstoffes simuliert werden. Hierbei konnten, neben den durch Lösungsmittelextraktion identifizierten Geruchsstoffen, auch leichter flüchtige Substanzen identifiziert werden. Es konnte somit gezeigt werden, dass die 
Thermodesorption eine schnelle und effektive Methode für die Identifizierung der Geruchsstoffe während eines Schmelzprozesses darstellt.

Da Acrylat-basierte Produkte, wie Klebstoffe oder Farben, unterschiedliche Zusammensetzungen haben und damit viele Nebenprodukte auftreten können, wurden im vierten Teil der Arbeit unterschiedliche Ester der Acrylsäure synthetisiert und auf geruchsspezifische Eigenschaften, wie Geruchsqualitäten und Geruchsschwellenwerte, sowie chromatographische und spektrometrische Eigenschaften untersucht. Hierbei wurde gezeigt, dass Strukturanaloga bekannter Geruchsstoffe mit ähnlichen Geruchseigenschaften beschrieben werden konnten. Eine zukünftige Identifizierung unbekannter Verbindungen wird auf Basis derartiger sensorischer und analytischer Daten wesentlich erleichtert. 


\section{Introduction}

\subsection{Adhesives}

Adhesives are non-metallic substances, which are able to hold adherends together by surface attachment [1]. Thereby the same, but also different materials can be bond together, enabling adhesives to be a ubiquitous joining process [2].

\subsubsection{Historical development of adhesives}

The oldest proofs for the usage of adhesives are stone flakes which are covered by birch-barktar and are approximately 180.000-200.000 years old [3]. This birch-bark-tar is produced by a dry distillation of birch-bark [4]. Much later, about 3000-1500 B.C., Sumerians and Egyptians used bituminous cements, animal and casein glues for their applications in construction and woodworking [2,5]. In 1690 the first commercial glue plant was founded in Holland [5]. In the following centuries the adhesive industry began to rise and U.S. patents on casein glues and starch adhesives were issued [5]. Also a German patent for natural rubber-based pressuresensitive adhesives (PSA) for the application in plasters was developed by Paul C. Beiersdorf in 1882 [2]. Nevertheless those PSAs could not achieve the requirements for industrial application [2].

In 1909 the first synthetic organic adhesive, a phenolic resin, was developed by Leo Hendrik Bakeland [2]. A few years later a patent for polyvinyl acetate, which is one of the most common adhesives until today, was issued [6]. Also polyurethane (developed by Otto Bayer) and acrylic adhesive first appeared in the 1930s [2,5,7]. All these synthetic adhesives can appear in different forms (see Chapter 1.1.2.), depending on the application. Even if the usage of synthetic adhesives is very diverse, natural adhesives are still used and were further improved in the last decades [8]. Until today, adhesives with new properties are developed, using novel monomers, polymers, copolymers and additives to reach new applications and better techno-functional properties. Scientists also learn from nature, trying to reproduce e.g. the defensing mucus secreted by slugs, which adheres to wet surfaces; such natural principles are then transformed to develop adhesive material that can bond to biological tissues [9]. The challenge is to develop products that are simple and cheap to produce, non-toxic and environmentally friendly, and that fulfill the diverse properties required of adhesives in different types of applications. 


\subsubsection{Types of adhesives and their classification}

Adhesives can be either classified with regard to their chemical basis or their mechanism of hardening. Figure 1 depicts a classification scheme according to chemical basis. Commonly, organic compounds derived from synthetic base moieties are the main technological principle [10]. This is due to the fact that synthetic products are characterized by higher bond strength and a greater aging resistance in comparison to natural basis adhesives. On the other hand, inorganic compounds can be used at higher application temperatures and are therefore more heat-resistant [10].

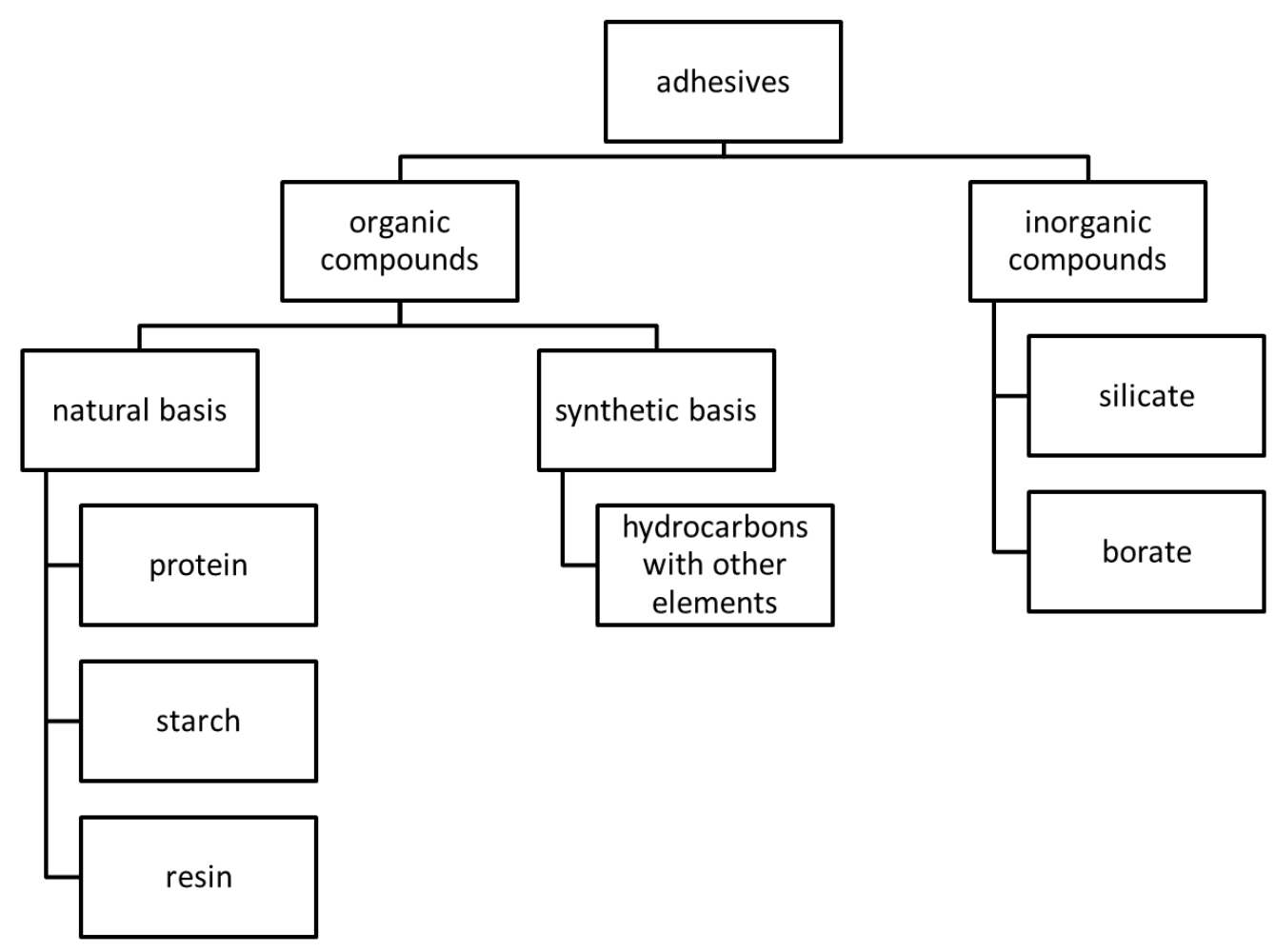

Figure 1: Classification of adhesives by their chemical basis; cited and modified from [10]

Natural adhesives are known since thousands of years, with hydrolyzates of connective tissue, bones, skin or starch being in use. These types of adhesives are used, for example, in paper industry, woodworking, the manufacturing of textiles or of corrugated cardboard [11-13]. Due to their low bonding strength, natural adhesives cannot be used for bonding metal, plastic or glass [10]. To solve this problem a wide range of synthetic adhesives is used, where the basic materials are hydrocarbons with reactive structural parts like double bonds or functional groups that subsequently form a polymer [10]. 
The second classification is by the mechanism of hardening (Figure 2). Here the main principles can be clustered into reactive systems, non-reactive systems and a combination of both, yielding the reactive hot-melts [10]. In the latter case, the bond is formed via cooling (non-reactive) followed by a chemical reaction, leading to a total hardening [2,10]. The main adhesives within this group are polyurethane- and epoxide resin-based adhesives.

Reactive system adhesives consist of monomers with reactive functional groups, which build up a polymer during application of the adhesive base formulation [10]. The chemical reaction is initiated by mixing two or more components prior to application. In one-component adhesives the reaction is started by heating, UV-radiation or humidity [2]. Monomers of the polymerization adhesives commonly comprise double bonds as reactive moieties. Typical representatives are polyvinyl acetate, polyacrylates or methyl acrylates with their respective monomers vinyl acetate or different esters derived from acrylic acid [10]. Polyaddition adhesives are formed by the reaction of different monomers building up epoxide resin and polyurethane adhesives [10]. Finally, reactive systems comprise polycondensation adhesives, which are formed by the reaction of two monomers thereby eliminating a molecule like water or alcohols [10]. The phenol-formaldehyde resin adhesive is representative of this group.

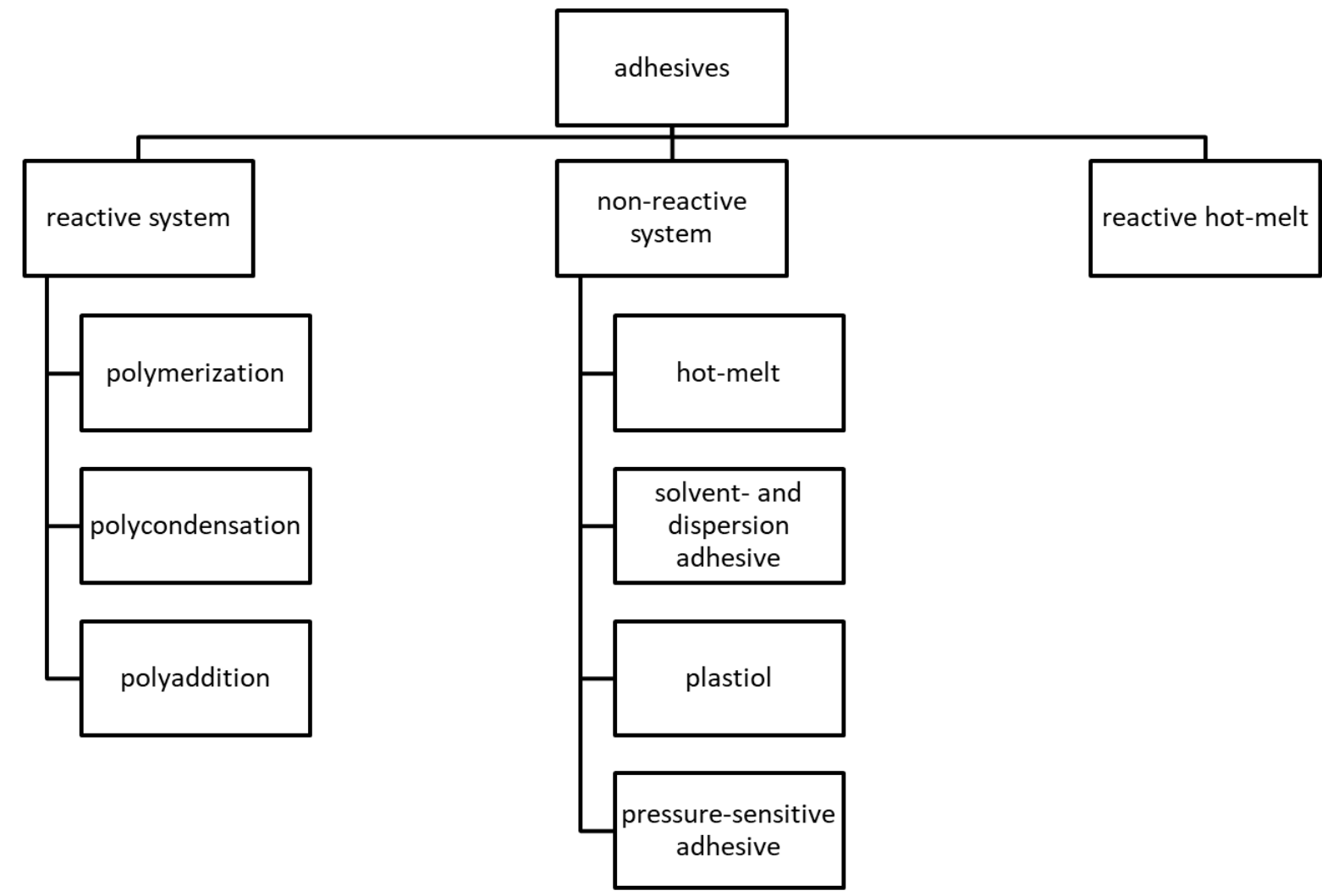

Figure 2: Classification of adhesives by their mechanism of hardening; cited and modified from $[2,10]$ 
Non-reactive systems are defined as polymers, which are either solved, dispersed or generated as a thermoplastic molten mass. These adhesives harden by a physical process like evaporation of the solvent or cooling of the molten mass [2]. Within the group of non-reactive systems, hot-melt adhesives are the first type of those. They are solvent-free, solid at room temperature and of high molecular weight [2]. Diverse polymers and copolymers like ethylene vinyl acetate can be used mixed with other compounds or additives like waxes, resins and antioxidants (described in chapter 1.1.3) [10]. These additives modify the properties, such as the melting point or viscosity of the hot-melts. The advantage of these thermoplastic adhesives is, that the adhesion-bond can be released by temperature and also rebuild [2]. In the case of plastiols, the polymer is dispersed in a plasticizer, which acts as a solvent [2]. During heating of the adhesive, the polymer, often polyvinylchloride, absorbs the plasticizer and forms a solid gel structure and the respective adhesion-bond [2,10]. Polymers that are solved or dispersed in a solvent or water harden by evaporation of the liquid phase and thereby form the adhesion bond [10]. PSAs are polymers with permanent sticky properties, that need a carrier, like a plastic or silicone film for their application [2]. As their name implies, these adhesives can be easily applied to the adherend by slight pressure. PSAs are predominantly used in applications comprising tapes for packaging or health care, as well as labels, and in the electrical and automotive industry, e.g. to attach cables or interior parts [14].

In this work we primarily focused on the analysis of acrylic adhesives. Acrylic adhesives are classified as organic systems on synthetic basis. Typical monomers of acrylic adhesives are butyl acrylate, 2-ethylhexylacrylate and several esters derived from methyl acrylic acid $[10,14]$. Acrylic adhesives as a group cover a wide range of hardening mechanisms, being either applied as reactive components as well as two-component systems, but also being used as hot-melts and pressure-sensitive adhesives [2,10,14,15]. Also the usage of the acrylate-based adhesives is very diverse as is their respective hardening mechanism. They are used in the construction sector as 1- or 2-component reactive systems, in the automotive sector, where PSAs are used as well as in the medical sector, like the analyzed elastic therapeutic tapes in this study. Due to their wide range of uses, humans are often in direct or indirect contact with acrylic adhesives and influenced by emissions and odorants of those. 


\subsubsection{Additives in adhesives}

Apart from the usage of different polymers and monomers, a series of additives are used, commonly at low levels, for the manufacturing of adhesives to impart special properties to the final product like the adhesion power, stickiness, stability, or viscosity $[10,16]$. In the following the main additives used in adhesives are described:

\section{Curing agent}

This class of additives is used to start a chemical reaction in reactive adhesives in order to build up the polymer structure [10]. To initiate a radical polymerization process e.g. peroxides are used whereas acids are applied to lower the $\mathrm{pH}$-value to promote condensation reactions. Metal-ions are also used as catalysts to initiate radical substitution reactions. These curing agents are added in low amounts to start the reaction but do not further influence the main properties of the generated polymers.

\section{Cross-linking agents}

These compounds are administered to form a 3-dimensional structure out of linear polymer chains, by adding reactive groups to the core chain moieties [10]. Usage of special crosslinking agents like isocyanatoethyl methylacrylate supports the formation of polymers that can be modulated with regard to chain lengths as well as tightness of the network structures, thereby enabling the manufacturer of generating adhesives with custom-made properties [17].

\section{Plasticizers}

The deformation properties of adhesives can be influenced by the addition of plasticizers. In addition to that the material is more flexible and the rheological properties can be modified [18]. By using hydrophilic or hydrophobic plasticizers the sensitivity to water can be regulated depending on the application [18]. The most common plasticizers are phthalates, adipates and benzoates, which are added in a range of 5-50\% related to weight $[16,19]$. These molecules increase the distance between the polymer chains, decreasing their direct interaction and thereby imparting more flexibility. Disadvantages of the use of plasticizers are the lower adhesion strength and the possible emission of plasticizers, that may cause a change of the properties of the adhesive in its wake [10].

\section{Waxes}

Waxes are primarily applied to hot melt adhesives (HMA) [10,20,21] and may comprise hydrocarbons, alcohols, acids and esters [10]. Wax materials are defined to have a melting point above $40^{\circ} \mathrm{C}$, a low melting-viscosity and no degradation at higher temperatures. Typical 
waxes used for HMA are Fischer-Tropsch-waxes, polyethylene-waxes, paraffin waxes and microcrystalline waxes. They are used to increase the stickiness and the general adhesion properties, but also to improve viscosity and stability of the product.

\section{Stabilizers and Antioxidants}

This class of substances is used to protect the adhesive against environmental damage, like oxidation or UV-induced degradation of the polymer necessitating the usage of antioxidants and light stabilizers [10]. Both primary or secondary antioxidants are commonly used [20]: free-radical scavenging or primary antioxidants, typically hindered phenols or secondary aryl amines, thereby inhibit the oxidative reaction via a chain-terminating reaction. Secondary antioxidants such as thioethers or phosphites react via a redox reaction with the generated hydroperoxides, thereby forming stable products and terminating further oxidative degradation.

\section{Solvents}

As stated above, solvents may play an important role in the manufacturing and application of adhesives (see chapter 1.1.2) [10]. Commonly, different solvents like water, acetone, butyl acetate, methyl ethyl ketone, xylene and others or combinations thereof are used, and are adjusted according to the respective requirements of the polymer taking into consideration its solubility or the desired mode of evaporation that such be achieved during the drying process.

\section{Resins}

Synthetic resins like aromatic or aliphatic hydrocarbon resins or, at times, natural resins like colophony are used to improve the stickiness and viscosity of adhesives [10]. Resins allow achievement of lower viscosities, thereby reducing the required amount of solvent; this in turn favors shorter drying times. Commonly, these resins are solid and brittle at room temperature, and soften with increase in temperature.

Other additives may be used for specific applications, such as catalysts accelerating the polymer-reaction, tackifiers increasing the stickiness of the adhesive and reducing the time required for sufficient bonding, or fillers improving the mechanical, chemical or physical properties of the final product by diverse modes of action [10]. Moreover defoamers are administered to reduce surface tension and to avoid formation of bubbles, as well as additives that improve the rheological properties of the product [10]. For adhesives containing hydrophilic and hydrophobic parts or particles, emulsifiers or dispersants are added to avoid decomposition of the adhesive [10]. To increase the bond between the adhesive and the 
adherend, surface primers or bonding agents are used serving as an additional connective link between both materials [10].

\subsubsection{Mechanisms of adhesion}

The connective interaction between two different bodies or materials is called adhesion [22]. To describe the mechanisms of adhesion, a series of theories have been developed to explain the chemical and physical interactions between their surfaces. The model of mechanical interlocking has been proposed by McBain and Hopkins [23] describing the interlocking of the adhesives into pores and other cavities of the adherend. However this mechanism does not describe the adhesion between smooth surfaces [24] requiring further theories to explain adhesive effects.

The chemical bonding theory describes the adhesion via a chemical bond formed by the adhesive and the substrate [24]. In this case, the formation of the bonds depends on the reactivity regarding both surfaces that may require both ionic as well as covalent bonds [24]. Additives like bonding agents, also known as coupling agents (see chapter 1.1.3), which are often silane-based compounds [25], can thereby improve the strength of such bonds [24]. Especially when bonding plastics together the diffusion theory is of relevance: it states that macromolecular polymer chains, or even whole segments of the adhesive as well as of the plastic material, diffuse into each other resulting in a merged interface [24]. This diffusion theory has been supported by Voyutskii [26]. To achieve such merged interface, the chains have to be sufficiently mobile and the polymer sufficiently soluble to form this type of bond [24]. De Bruyne, on the other hand, proposed the polarization theory [27] that refers to the bond strength being imparted by the polarity and dipole of the respective molecules $[10,27,28]$. Consequently, this theory does not refer to adhesive effects of nonpolar substances, but rather addresses polar structural parts of molecules that enhance bond strength [10]. Last but not least, the electronic theory, developed as early as in 1948, describes the formation of a double electrical layer at the interface that is effectuated by an electrical transfer between substrate and adhesive [24]. Consequently, this type of bond depends on the presence of electrons, ions or dipoles [10]. The thermodynamic theory by Sharpe and Schonhorn [29], at which the adhesion is connected to the capability of the adhesive to wetting the surface of the substrate.

All in all, for a comprehensive description of the mechanisms of adhesion, a single theory or concept generally provides an incomplete picture. Rather is it a combination of different 
chemical, physical and thermodynamic interactions between the adhesive and the adherend that needs to be regarded when aiming at a complete understanding of the basic principles of adhesion. The complexity of the diverse molecular structures and components that is commonly found in modern products, however, brings about that adhesion as a physicochemical phenomenon that even today is not yet fully understood; let alone the diverse modes of chemical interaction and potential compounds that are formed in the wake of formulation, production, polymerization and adhesion. This is not only true for mechanical aspects but also chemical reactions, as relates to the current work on odorant release and emission processes. 


\subsection{Physiological basis of odor perception}

The olfactory neuroepithelium is located in the upper part of the nasal cavity, which can be reached by odorants via the nose (orthonasal olfaction) or via the moth (retronasal olfaction) [30]. The nasal cavity is separated into two halves, in which the olfactory epithelium (OE) covers about $2 \mathrm{~cm}^{2}$ in each cavity [30,31] and the surface of the OE is covered by the olfactory mucosa. The $\mathrm{OE}$ is separated from the brain by the cribriform plate of the ethmoid, which is highly perforated, providing the olfactory nerve bundles access to the olfactory bulb (OB) [30]. It is the only part of the body where the central nervous system is in direct contact to the outer surface [30]. The olfactory nerves concentrate multiple axons of olfactory neurons, form nerve bundles and convey the impulse into the OB [30].

The $\mathrm{OE}$ is about $60 \mu \mathrm{m}$ in height and is composed of several cell types, the olfactory sensory neurons (OSN), sustentacular cells, stem cells and Bowman's glands [30]. OSNs are located in the epithelium, and about 10-25 cilia are located at the apical surface of the OSN [32]. Their plasma membrane contains the olfactory receptors (OR) [32]. OSNs persist only for a few month and are replaced by new neurons, which are created in the same manner as the original neurons [33]; in the wake of this process, the OE is protected against damage and regenerated.

To achieve odor perception, the odorants diffuse into the aqueous mucus before reaching the OR [30]. Hydrophobic molecules, which are not soluble in the aqueous mucus, are carried through the mucus by odorant-binding proteins (OBS) [34]. These OBS can also directly interact with the ORs by modulating their function [35] and clearing the odorants from the receptors [36]. The role in humans, however, is unclear today [37].

The olfactory receptors belong to the group of G-protein coupled receptors (GPCR) which are encoded in about 800 genes, in which only 396 are intact [30,38]. Each OSN expresses only one single OR gene [30]. The ORs contain a seven trans-membrane-structure, which forms a pocket in which the odorants can bind [30]. Binding of an odorant is followed by a cascade of enzymatic reactions [30,39] (Figure 3). ORs are connected to a $G_{\text {olf }}$-protein, in which the $\mathrm{G}_{\text {oolf }}$-Subunit is activated. Subsequently, the type III adenylate cyclase (AC) is activated by the $\alpha$-subunit, which hydrolyses ATP to cAMP. cAMP binds to the cyclic nucleotide-gated channel, which allows the influx of calcium and sodium cations. Intracellular $\mathrm{Ca}^{2+}$ induces the opening of chloride channels, enabling the efflux of chloride ions and amplifying the depolarization of the cell. The electrical signal is transmitted along the olfactory neurons to the glomeruli in the olfactory bulb, being tightly connected to the brain [40]. 


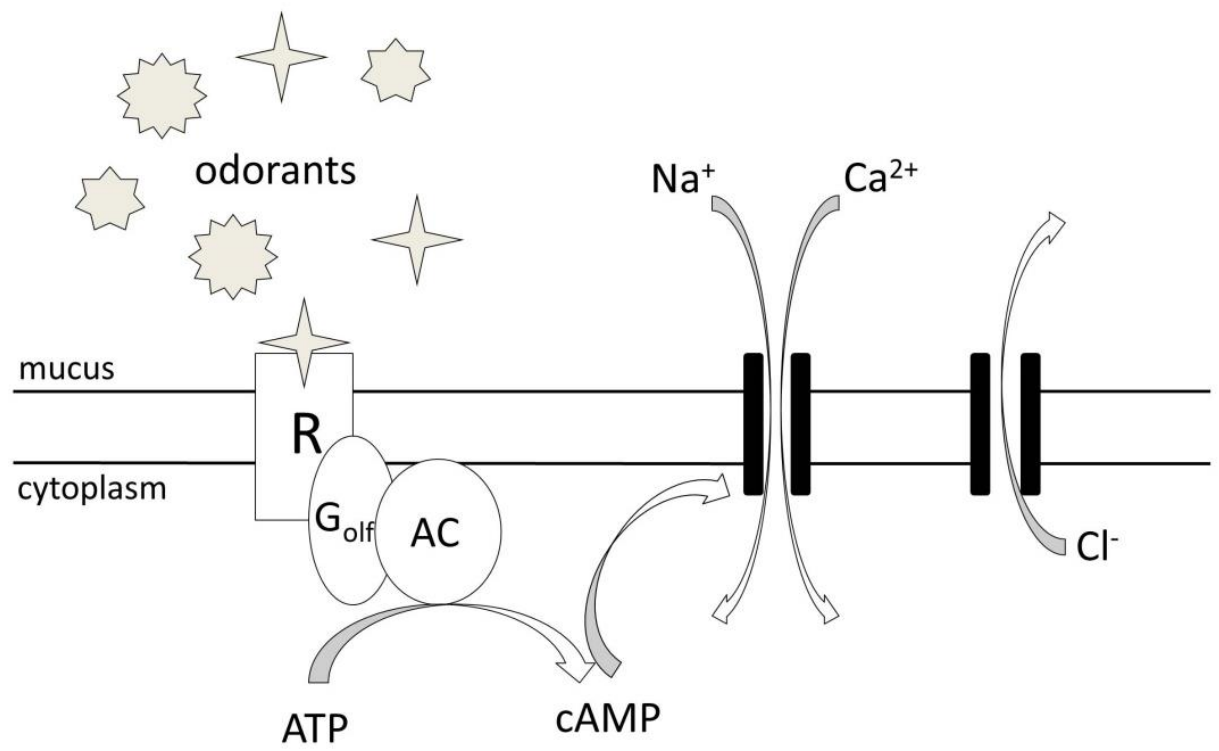

Figure 3: Schematic mechanism of odor perception

R: Olfactory receptor; $\mathrm{G}_{\text {olf }}: \mathrm{G}_{\text {olf-protein; }}$ AC: adenylate cyclase type III

The human olfactory system is able to perceive thousands of odorants, despite the fact that only 396 different olfactory receptors are available. This implies that odorants can bind to different ORs, and one OR can likewise recognize different molecules [41,42]. Nevertheless, recent studies imply that some receptors are rather broadly tuned whereas others are highly specialized to characteristic molecules [30]. Accordingly, a combinatorial coding has been proposed to explain the wide range of detectable odorants [30]. Also different concentrations of odorants can affect the activation of different ORs [42]. I.e. in the case of some thiols, smell perception deviates with concentration level [43]. Moreover, so-called perireceptor events may further modulate the smell perception of specific molecules by derivatization of the inhaled substances via odorant metabolizing enzymes (e.g. Cytochrome P450) [44]. The divergent percept may not only derive from the changed chemical structures but also from their change in polarity and solubility, e.g. in the olfactory mucus layer.

Apart from these general physiological considerations olfactory perception in humans can be influenced by a multitude of factors. Especially age can heavily influence the detection of odorants; it has been proposed that this is caused by damaging of the olfactory epithelium as a consequence of viral and environmental impact or the loss of selectivity of the receptor system to odorants [45]. Apart from that, gender, smoking habits and ethnicity have been 
shown to result in different odor perception. Thereby, young females have been reported with generally the highest olfactory acuity [46].

Odorants, or better chemical stimuli, can not only activate the olfactory system, but also the trigeminal system [47]. Here almost all odorants can activate the trigeminal system in high concentrations [48], eliciting pain- or temperature-like sensations such as burning, cooling or pungency. These effects are mediated by the trigeminal nerve, which consists of three branches, comprising chemoreceptors of the transient receptor potential (TRP) family [47]. Both temperature and chemical substances have sensitivity to these ion channel receptors [49]. 


\subsection{Odor analysis}

\subsubsection{Sensory evaluation}

The purpose of sensory analysis is to elucidate the objective responses to the properties of samples, mediated by the human senses [50]. In general sensory evaluations the overall odor of a sample is evaluated, whereas during GC-O analysis the odor of chromatographically separated molecules is recorded. The main drawback is, accordingly, that additive, suppressive as well as synergistic effects of individual odorants are not captured in the course of such GC-O analyses, but can only be evaluated by additional sensory tests. Such effects have been repeatedly reported, and have even been found to affect the odor thresholds of odorants $[51,52]$.

The arsenal of sensory methods can be generally separated into two main approaches: discriminant methods and descriptive methods [50]. In each case, a sensory panel is necessary for the evaluation. When performing a descriptive analysis, the panelists have to be trained, motivated and need to attend the training regularly [53]. In discriminant analysis, however, untrained panelists can participate more easily as they do not require such deep level of training.

A discrimination test is designed, as evident from its name, to elaborate whether two or more samples are different or not [50]. Depending on the task, different tests such as duo-trio, paired comparison and triangle tests have been established. In the course of the paired comparison test, two products are presented and the panel is asked to indicate which product exhibits a special characteristic to a higher extent [50,54]. Nevertheless, it has been shown that panelists tend to detect differences in any case and are distracted by minor irrelevant cues such as the design of the test sheet [54]. The most commonly used discrimination test is the triangle test, where panelists are asked to identify those two samples out of three samples that are the same, or, vice-versa, to indicate which sample is most different from the others $[50,54]$.

A descriptive analysis is used to determine the presence or intensities of particular characteristic features, it commonly comprises both the identification and quantification of predefined sensory features [50]. This method may even provide further information that helps identifying the cause of a specific difference [50]; i.e. a specific smell may indicate the presence of specific odorants or a whole substance class such as free fatty acids in rancid milk products. The most commonly used method is a sensory profile analysis. The panelists first 
agree in a consent decision on the sensory attributes, and then rate these on a predefined scale. The individual results obtained from the panel are averaged and are visualized by a graph, commonly a spider-web diagram [53]. Additionally, a hedonic rating can be performed. The scale for this test corresponds to a liking continuum from "like extremely" to "dislike extremely" [55].

With regards to the current thesis, sensory changes due to technological steps may be of relevance. For example, non-food materials may be exposed to continuous temperature and environmental effects during storage, or may get heated during manufacture or use. Therefore sensory analysis may comprise such a processing step to represent or simulate these conditions, and to allow for a sensory comparison of treated and untreated sample.

\subsubsection{Isolation and sampling methods for volatile compounds}

Sample preparation and isolation or enrichment of odorants is one of the main challenges in smell research, and depends on various factors. Odorants belong to diverse chemical substance classes and cover a wide range of polarities, solubilities, vapor pressure activities and $\mathrm{pH}$ values [56-59]. Accordingly, the vast world of odorants comprises chemically rather unstable compounds, which may generate other compounds, e.g. by reaction with oxygen or heat [57]. Apart from that, concentration levels can be very low whereas sensorially irrelevant molecules may accompany the target molecules, and make their detection a real challenge [56-58]; accordingly, an isolation and/or enrichment procedure may be required [57]. Potent trace compounds can highly influence the overall odor of a sample alone or in combination, whereas their odor threshold is very low. This is the case for example for 1-p-menthene-8-thiol, which was found as an aroma compound in fresh grapefruit juice [60], and is known as the substance with the lowest odor threshold eliciting a "grapefruit-like" odor impression [61]. Thereby, matrix effects may heavily influence the isolation of odorants [57]. The odorous compounds are normally distributed throughout the whole matrix and are not only located at the surface of a sample. Therefore shearing methodologies prior to the extraction can increase the amount of extractable compounds. Nevertheless, especially in nonfood materials, a large number of non-odorous volatiles are present potentially disturbing the extraction of odorants. Another factor is the volatility of the compounds, which can range from boiling points below room temperature to liquid or solid aggregate states under the same conditions [57]. All these factors can make exhaustive recovery of all odorous compound of a sample complicated challenge. As a thumb-rule, the overall smell of the isolated volatiles 
should be representative for the overall odor impression of the original sample [59]. Hereby the critical step is the separation of the volatiles from the matrix. An insufficient extraction of the odorants can lead to an incorrect result by determining odorants with wrong odor potency compared to the original sample.

A large number of different techniques and methods for the isolation of odorants have been established nowadays. The choice of the right methods depends on the analytical problem, the target compounds/odorants and the sample matrix itself. In general there are two different main methods for the extraction of volatiles, namely solvent-free and solvent-based approaches, as described in the following:

\section{Solvent free methods}

The main advantage of this group of techniques is that no solvent is required. Accordingly, the handling of those methods is easier, time saving and avoids contact with hazardous chemicals. Also, analysis of highly volatile compounds can be achieved; this is especially preferable in cases where compounds normally elute with the solvent peak in solvent based extraction. Furthermore during a solvent extraction the compounds are extracted according to their polarity in comparison to the polarity of the solvent. When using headspace and thermal desorption approaches this effect can be excluded. In odor and aroma research five solventfree methods are state-of-the-art:

\section{Solid phase micro extraction (SPME)}

SPME was developed in 1988 by Berlardi and Pawliszyn for the analysis of environmental chemicals in water [62], and then further developed [63-65] and adopted for the analysis of odorous compounds [66-69]. The fiber material consists of a short fused silica fiber coated with a specific adsorbent, which is selected according to the matrix and the target compounds [58,59]. Typical coatings are polydimethylsiloxane, polyacrylate, divinylbenzene and carboxen or mixtures of those $[69,70]$. They directly influence the amount and character of the adsorbed compounds [71], making a broad odor characterization of a sample difficult, because of discrimination of substance classes. The adsorption is based on the interactions of the fiber-material with the volatile compounds, and relates strongly to the respective polarity of analyte and adsorber material. Thereby, the sample matrix can significantly affect the extracted odorant amount [71]. In non-food materials the high content of volatile odorless compounds can heavily influence the extraction of the target substances. The fiber can be immersed directly into a aqueous sample or into the headspace above a sample $[58,69]$; here 
the sensitivity of Headspace-SPME is much higher than static headspace approaches [72,73]. To obtain reliable results, sample volume, extraction time and temperature have to be controlled [69]. For analysis, compounds are normally subjected to thermal desorption in the gas chromatograph injector [69].

\section{Stir bar sorptive extraction SBSE}

This method was developed by Baltussen et al. in 1999 [74]. The stir bar consists of a metal core, which is coated with absorbents. Normally polydimethylsiloxane (PDMS) is used in a thick layer. The extraction mechanism is comparable to SPME with sorption of the analyte onto the extraction medium [70,75]. Here the extraction of polar compounds shows a lack of efficiency due to the hydrophobic character of the PDMS [76,77]. New upcoming polymeric phases may solve this problem [75]. Liquid samples can be extracted directly by stirring continuously, but headspace-SBSE approaches can also be realized [75]. For the desorption special desorption units, directly connected to a gas chromatograph, are used [70]. The main advantage compared to SPME is the higher capacity, higher quantitative recoveries and, correspondingly, a decrease in detection limits [75].

\section{Direct thermal desorption}

The principal of this methodology is the direct thermal desorption of the volatiles from the sample without or little sample preparation $[78,79]$. The volatiles are flushed by a continuous carrier gas flow onto a cooling trap, enabling the focusing and enrichment of the released volatiles. For desorption of the volatiles, the temperature should raise fast to a temperature that should ideally not alter the chemical composition of the sample to a relevant extent [80]. Due to the elevated desorption temperatures this method is only suitable for samples containing stable compounds, and that do not generate thermally induced artifacts. The direct thermal extraction is especially useful when extracting semi-volatile compounds, and may be superior compared to other solvent-free methods [81]. Due to the fact that many non-food samples are heated during manufacturing, one can propose that unstable compounds would be degraded during this process, so that this methodology can be deemed suitable for a fast screening for odorants of such samples.

\section{Static and dynamic Headspace}

Different approaches have been employed for the analysis of VOCs in the headspace of a sample, namely static headspace and dynamic headspace analysis [82]. Using these techniques it is possible to analyze the vapor phase above a sample [83]. The advantages here are the relatively low costs, a simple sample preparation, the rapid separation of volatile 
compounds from the matrix, the required small amounts of sample for analysis and avoidance of artifact formation $[59,82]$.

For static headspace analysis the sample is placed in a container under controlled conditions. After equilibration a headspace sample is withdrawn via a septum and directly injected into a gas chromatograph [58]. This method has first been described in 1963 [84]. The main disadvantage is the low sensitivity of this method $[58,82]$.

As the name implies, in dynamic headspace analysis the analytes are swept off the matrix applying a constant inert carrier gas stream (e.g. nitrogen) $[59,82,83,85]$. The volatiles are collected and enriched on a cryogenic trap or on an adsorptive material, resulting in higher sensitivity $[58,85]$. Desorption of the trapped analytes can be achieved using solvents [86] or thermal desorption [87].

Disadvantages are the low yield of odorants in the headspace going along with the problem of olfactory detection of these low substance concentrations; this is especially true in the case of substances with relatively high odor thresholds and low volatility and liberation from the matrix, respectively [83]. This goes along with the fact that the concentration of odorants in the headspace does not directly represent the concentration in the sample [59].

\section{Solvent-based extraction}

Solvent extraction and distillation methods commonly generate complete odor extracts [59]. In this approach, the solvent is directly added to the sample.

\section{Direct solvent extraction}

Direct extraction of the matrix is in most cases a simple and convenient but also resourceintense technique on condition that no emulsification takes place that poses problems in later separation [57]; it is the first step to obtain odor extracts from a sample [58]. Commonly solvents like hydrocarbons, pentane, diethyl ether, mixtures of both, or dichloromethane (DCM) are used [57]. The obtained extracts can be directly analyzed if applicable to e.g. GC analysis, or after removal of components such as non-volatile constituents or preconcentration via (partial) removal of the solvents. Obtained extracts may be very complex in composition, due to potential co-extraction of a series of matrix constitutes. Moreover, co-eluting volatile compounds may interfere in the identification of the odorants, which can be solved by additional, mostly time-consuming fractionation steps [59]. Fractionation may favor the loss of highly volatile compounds and artifact formation, e.g. due 
to thermal degradation. Overall, this method shows good reproducibility and sensitivity, especially for trace odorants on condition that the issue of coelution is resolved [57].

\section{Solvent assisted flavour evaporation (SAFE)}

The solvent assisted flavour evaporation has been developed by Engel et al. in 1999 [88], and is one of the most commonly used extraction methods for odorants. In this approach a solvent extract of a sample or liquid samples is added drop-wise via a dropping funnel to the distillation apparatus, which is thermostated to $35-50^{\circ} \mathrm{C}$. The whole apparatus is put under high vacuum. The volatiles therefore evaporate instantaneously, and are then transferred to a second flask, cooled with liquid nitrogen. All non-volatile compounds remain in the first flask, thereby purifying the extract.

The obtained solvent extract is further concentrated via Vigreux-distillation and microdistillation [89]. Ideally, the smell of the obtained extract should then be representative for the original sample. The main advantages of this technique, due to the mild distillation conditions, are the avoidance of artifact formation and degradation of instable compounds. Moreover, the yield of polar substances and of substances from fatty matrices are higher [70]. This method has initially been developed for analysis of food aroma, but diverse studies show that the methodology is also applicable for odor analysis in the non-food sector [90-98].

\section{Simultaneous distillation-extraction}

The simultaneous steam distillation-extraction has been established by Likens and Nickerson in 1966 [99]. The general principle is that a small amount of an extracting solvent and the liquid sample or an aqueous solution of the sample is placed in two separate heated flasks. The odor-active compounds are recovered from the matrix by coupled solvent extraction and steam distillation. Condensation of the vapor phase takes place in the upper part of the apparatus bridging both flasks. The odorous compounds are thereby transferred into the organic phase. Simultaneously, both phases are condensed and recirculate within the corresponding flasks. The liquids are continuously processed for up to 48 hours [100]. The advantage of this method is that the volatiles are extracted and concentrated within a single operation step; accordingly, only a limited amount of solvent is required due to the circular process [57]. To this aim, pentane, diethyl ether, chloroform and dichloromethane are normally used as steam distillable solvents $[57,100,101]$. To avoid high temperatures and to reduce the boiling point of the liquids the apparatus is commonly operated at reduced pressure [58,59]. The recoveries of the compounds are generally high [57]; nevertheless, some studies report low recovery for highly volatile compounds [102,103]. Moreover, 
decomposition of labile compounds and the formation of artifacts in the course of extraction have been reported, mostly being associated with oxidation and thermal reactions $[58,59,100]$.

\section{Steam distillation}

The steam-assisted distillation method is a traditional procedure for the isolation of volatiles from odorous samples [101]. The sample is dispersed in water and heated in a flask [57]. Steam-distillable compounds are removed from the sample and condense together with the aqueous phase; this step is followed by a solvent-extraction. Problems of this method are the insufficient extraction of polar and low volatile compound with boiling points greater than $100^{\circ} \mathrm{C}$ [57], both qualitatively and quantitatively [104]. Also bumping, foaming and the thermal degradation of odorants and neoformation of substances can be a disadvantages when applying steam distillation [57]. The main advantage is the simple and fast separation of volatiles and non-volatiles [57].

\subsubsection{Gas chromatography-olfactometry}

In the group of volatile compounds only a small part of the VOCs can be perceived as odorants by humans. The concentration of the substances must be higher than their respective individual threshold to be perceivable [56,105]. In modern odor research, one of the most important analytical methods for detecting odorants is gas chromatography-olfactometry, which was first developed by Fuller et al. in 1964 [106]. This technique enables the differentiation of odor-active and odorless volatiles [107], using the human nose as a sensitive detector to analyze the chromatographic effluent in view of odorous molecules. Thereby, the effluent is commonly split, with one part of the gas stream being guided to an odor detection port (ODP), and the second in parallels to a second analytical detector like a flame ionization detector (FID) or a mass spectrometer; this allows for simultaneous detection and assignment of the perceived odor to the respective peak. The reliability of the GC-O data can be affected by different parameters like the type of odorant recovery and enrichment prior to GC analysis. Apart from that, analytical parameters like polarity of the column and temperature program, as well as performance of the assessor can influence the chromatographic separation and thereby the GC-O results $[105,108]$. Success of GC-O strongly depends on the skill, training, and day-by-day performance of the assessor. Additionally, several assessors should perform GC-O to avoid the underestimation or even non-detection of odorants, e.g. due to anosmia [105]. A schematic presentation of a GC-O system is shown in Figure 4. 


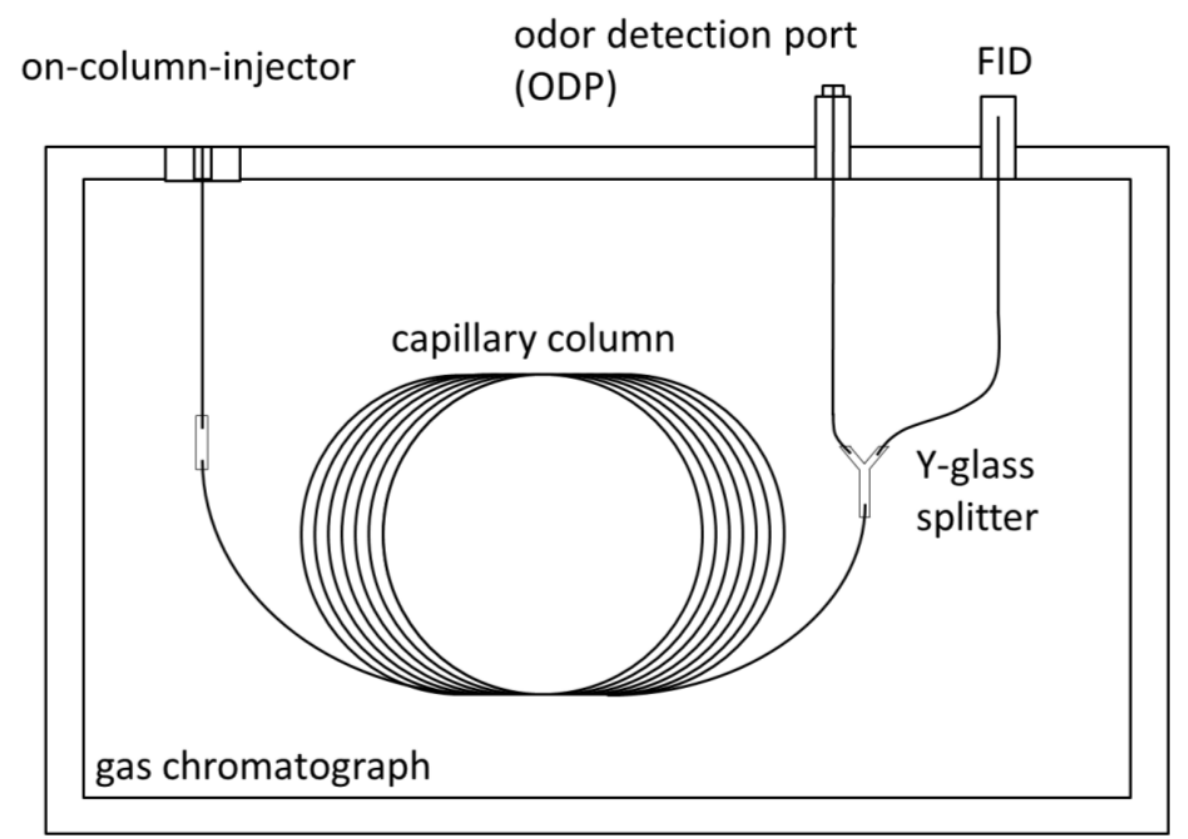

Figure 4: Scheme of a gas chromatography-olfactometry system consisting of an on-column injector, a capillary column, a FID and an ODP, all comprised within or on an GC oven.

The impact of a single volatile compound to the overall odor of a sample cannot be determined by a single GC-O analysis only. Three main methods have been developed, which are based on different principals, for recording GC-O data as well as screening the potential impact of single compounds to the overall odor [59,105,107,109].

Generally, there are so-called dilution to threshold techniques established: representative is the CharmAnalysis, developed by Acree [110,111] and the aroma extract dilution analysis (AEDA), developed by Grosch et al. [112-114]. Here, the solvent odor extract is commonly diluted stepwise using the same solvent, in most cases by a factor of 2 or 3 by volume. Each dilution is then assessed using GC-O. The assessor records the respective odor perception as well as the odor descriptor in the course of the chromatographic separation. For AEDA, the dilution in which an odor is still perceivable is defined as the flavor dilution factor (FD-factor). The odorants with high FD-factors are, first, assumed to have the highest impact on the overall odor of the sample. This approach has been chosen as basis for the current thesis. The terms aroma and flavor, however, are closely connected with food; as this thesis deals with non-food samples, these terms have been modified to odor extract dilution analysis (OEDA) and odor dilution (OD)-factors. 
Another approach is the CharmAnalysis that additionally records the duration of the perceived odors, yielding a kind of olfactometric representation of a chromatographic peak, which can then be integrated. Unlike AEDA, accordingly, the CharmAnalysis takes the peak shape and peak width into account.

Overall, the dilution factors in AEDA are in most cases comparable to the area weighting determined by Charm [105]. However, the dilution to threshold techniques are very timeconsuming, especially when using 8 to 12 dilutions or multiple assessors or assessments for one type of analysis. In Charm Analysis a minimum of three different panelists are required to repeat the experiment [59]. The same is recommended for AEDA or OEDA, respectively.

Direct intensity techniques use a scale to rate the momentary intensity of an odor perceived during GC-O. The most common method is called Osme [115,116], a dynamic time-intensity GC-O method. Thereby the odor intensity is rated by the panelists using a computerized 16-point scale time-intensity device [107]. The technique provides odor intensity peaks called Osmegrams, analoguous to an FID chromatogram. The technique saves time when working with well-trained assessors [107]. Nevertheless it takes a lot of training sessions to obtain individual reproducibility and agreement within the panel [105].

The third method is the detection frequency technique. This method has been described in several studies [117-119], and has been further developed by Pollien et al. [120]. Here, a panel of assessors carries out a collaborative GC-O analysis on the sample extract. Each assessor records the duration of the smell perception, and provides a smell description. This technique does not necessarily require a trained panel, but rather a minimum of 8-10 assessors. The results of the whole panel taken together generate an aromagram, in which the peak height corresponds to the number of panelists that detected the odor. The height of the peaks was termed nasal impact frequency (NIF) and the peak areas as the surface of NIF (SNIF).

When analyzing complex polymer matrices, odorants may be covered due to coeluting substances, a problem that can be addressed by a change of the stationary phase, but only in cases where no coelution occurs on the alternative phase [105]. In case that coelution still occurs, various methods may be applied to resolve this problem, such as heart-cut GC-GCMS, GCxGC-MS, or conventional separation steps such as column chromatography or liquidliquid extraction prior to GC analysis. The commonly used method for optimized substance resolution in odorant analysis is two-dimensional GC-O analysis that combines the heart-cut 
approach with simultaneous detection using an analytical detector and an ODP. A schematic setup of typical two-dimensional GC-O system is provided in Figure 5. Thereby regions of interest can be transferred via heart-cut separation to a second capillary column comprising a stationary phase of different polarity, thereby removing potential co-eluting substances from the separation in the first dimension [105].



Figure 5: Scheme of a 2-dimensional gas chromatography-olfactometry/mass spectrometry (2-D-GC-O/MS) system; containing two gas chromatographs connected via a cooling trap and equipped with capillary columns of different polarity

\subsubsection{Identification criteria for odorants}

The obtained GC-O data, comprising odor quality, odor intensity and OD-factor, provide only limited information about the underlying chemical structure of the odorants. For the elucidation of the odorous compounds different analytical methods are accordingly used.

The identification is based on the comparison of analytical data to known reference compounds [121]. In the field of non-food materials the availability of odorous reference compounds is limited and may require synthesis and establishment of a reference library. Identification criteria commonly recruited for the unambiguously identification of an odorant are, amongst others, the retention indices on capillaries of different gas chromatographic separation capillaries $[122,123]$. Retention indices are commonly calculated with respect to the relative position of the substance peak to other reference compounds, commonly a homologous series of n-alkanes. As a result, the obtained value depends on the stationary phase of the column only and is mostly independent of the applied analytical conditions, i.e. the temperature program or gas flow. For higher diagnostic value, retentions indices can be determined on different capillaries with different polarities. 
Another important criterion is the mass spectrometric data of a compound either yielding information on the molecular weight of a compound (primarily in chemical ionization mode), as well as structural information based on characteristic fragmentation pattern.

The third analytical parameter is odor characteristic (odor quality and odor intensity/potency), as retention indices and mass spectrometric data often do not allow unequivocal identification of a compound. Here, the human nose serves as a selective and sensitive sensor for identification. Information on odor qualities is often inconsistent in literature. Accordingly, comparison to reference compounds via GC-O analyses is required. Today, retention indices on two capillaries, mass spectrometric data and odor quality and intensity in comparison to reference compounds are the standard for odorant identification in aroma and odor research [56,121]. In case that no reference compound is available, ${ }^{1} \mathrm{H}-\mathrm{NMR}$ and ${ }^{13} \mathrm{C}-\mathrm{NMR}$ are applied for further structural information, on condition that sufficient substance material can be isolated for analysis [56].

\subsubsection{Quantification of odorous compounds}

After successful identification, a quantification of the odorants with the highest impact, revealed by OEDA, is commonly carried out. Based on these results, a so-called odor activity value $(\mathrm{OAV})$ can be calculated for each individual substance $[124,125]$. This value is calculated by dividing the concentration of an odorant in the samples through the odor threshold of the same compound in the respective matrix. The higher the OAV, the higher is the impact of the odorant to the overall odor of a sample. The OAV serves as a screening tool to elaborate those substances that most likely contribute to the overall aroma of a sample. Nevertheless additive, synergistic and suppressive effects cannot be elucidated via this approach only; reconstitution experiments would then need to be carried out to confirm the respective sensory effect [56]. In non-food material the main goal is to reduce the odor of a sample. Therefore the quantification is important to know the existing concentration and develop avoidance strategies to reduce the concentration below the odor threshold or remove the odor completely.

In case of unstable, reactive, or trace compounds specific targeted analyses are required [56,70]. To address these challenges, stable isotope dilution assays are commonly the method of choice in aroma and smell research [126-128]. Thereby, isotopic labeled standards (commonly comprising deuteration or ${ }^{13} \mathrm{C}$-labelling) are added in a known concentration to the material prior to the extraction procedure. Thereby deuterated compounds are commonly 
used. Only in case of a potential deuterium/proton exchange ${ }^{13} \mathrm{C}$-labeled compounds are recommended. The unlabeled and labeled compounds have almost similar chemical and physical properties. Accordingly, losses during the workup procedure are compensated since these affect both substances in the same way. During GC analyses the compounds are not separated from each other, but by mass spectrometry the labeling enables to distinguish between the internal standard and the target compound.

The concentration can be calculated via the ratio of the isotopic labeled and unlabeled compound, whereas calibration is achieved based on different mixtures of analyte and labeled standard. The method stands for its accuracy and precision even at trace concentrations $[56,127,129]$. Other methodologies can also be suitable for odor quantification, especially if the odorants in the sample are the main constituent. Often, isomeric compounds, which are not present in the sample, are used as internal standards. All in all, usage of the respective standard procedure for quantification is dictated by the concentration of the compound in the sample, the matrix composition, substance isolation and enrichment procedure and, of course, availability and cost of standard material. 


\subsection{Aims and outline}

Adhesives are known to emit a strong, unpleasant odor. Nevertheless studies dealing with odorants in adhesives are rare and often main compounds or solvents are referred to as reason for smell problems.

In order to close this gap in information and to generate first insights into the causative odorants, different types of acrylate based adhesives were investigated by means of GC-O, OEDA and (2-dimensional-) GC-MS/O in the first study (chapter 2). These types of adhesives are known to be associated with strong odors. Using these techniques, several odor active monomers were identified that revealed high OD-factors, besides several trace compounds with high impact on the odor of the adhesives.

As representative products, different elastic therapeutic tapes containing adhesive materials were analyzed in a second step, and were also found to emit unpleasant odors (chapter 3 ). These tapes were composed of an acrylic adhesive associated with cotton and spandex fiber. In this case, odorants with the highest smell impact were found to be by-products of the adhesive material such as 2-ethyl-1-hexanol.

Another major field of application of adhesives is hot melt adhesives. These materials contain waxes, which can be either Fischer-Tropsch or polyethylene waxes. The choice of the right type of wax is important to produce low odor products. Therefore an odor analysis was performed for different waxes, in order to elucidate and rate the odor potency of the wax samples and to identify the respective causative odorants (chapter 4). Another part of this study was the development of a direct thermal desorption-based extraction of the volatile compounds. Here the simulation of the melting process, comparable to the temperature regime used during application of the hot melt adhesives, was performed. The goal was to have a fast and simple method for the screening of odorants.

In the course of the study a series of acrylates were newly discovered. With the exception of butyl acrylate, however, there were no reports on the odor character of acrylates. The next aim of this study was, accordingly, to synthesize different types of acrylic esters, containing various structural motifs, and to establish the respective structure-odor activity relationships (chapter 5). The olfactory, chromatographic and spectrometric properties of the synthesized and commercially available acrylic esters provide now a comprehensive database of these substances, and support future identification of such odorants in acrylate-based products. 
Characterization of the odor of adhesives, their odorant composition and the here developed direct thermal desorption approach for analysis are the foundation for future studies in the field of odorant analysis in adhesives. They are an important starting-point for targeted optimization of such products with regard to smell. 


\subsection{References}

[1] Gutcho M. H., Torrey S. (1983) Adhesives technology: developments since 1979.

[2] Brockmann W., Geiß P. L., Klingen J., Schröder B. (2005) Klebetechnik Klebstoffe, Anwendungen und Verfahren. WILEY-VCH Verlag GmbH \& Co. KGaA,

[3] Mazza P. P. A., Martini F., Sala B., Magi M., Colombini M. P., Giachi G., Landucci F., Lemorini C., Modugno F., Ribechini E. (2006) A new Palaeolithic discovery: tarhafted stone tools in a European Mid-Pleistocene bone-bearing bed. Journal of Archaeological Science 33 (9):1310-1318

[4] Kozowyk P., Soressi M., Pomstra D., Langejans G. (2017) Experimental methods for the Palaeolithic dry distillation of birch bark: implications for the origin and development of Neandertal adhesive technology. Scientific reports 7 (1):8033

[5] Keimel F. A. (2003) Historical development of adhesives and adhesive bonding. In: Pizzi A, Mittal K (eds) Handbook of Adhesive Technology. pp 1-12

[6] Bravo A., Hotchkiss J. H., Acree T. E. (1992) Identification of odor-active compounds resulting from thermal oxidation of polyethylene. Journal of Agricultural and Food Chemistry 40 (10):1881-1885

[7] Skeist I., Miron J. (1981) History of adhesives. Journal of Macromolecular ScienceChemistry 15 (6):1151-1163

[8] Skeist I., Miron J. (1990) Introduction to adhesives. In: Handbook of adhesives. Springer, pp 3-20

[9] Li J., Celiz A. D., Yang J., Yang Q., Wamala I., Whyte W., Seo B. R., Vasilyev N. V., Vlassak J. J., Suo Z., Mooney D. J. (2017) Tough adhesives for diverse wet surfaces. Science 357 (6349):378-381. doi:10.1126/science.aah6362

[10] Habenicht G. (2009) Kleben Grundlagen, Technologien, Anwendungen. 6. Auflage edn. Springer-Verlag Berlin Heidelberg,

[11] Brandis R. L. (1990) Animal glue. In: Handbook of Adhesives. Springer, pp 123-134

[12] Kruger L., Lacourse N. (1990) Starch based adhesives. In: Handbook of adhesives. Springer, pp 153-166

[13] Pearson C. L. (2003) Animal glues and adhesives. Handbook of adhesive technology:479-494

[14] Temin S. C. (1990) Pressure-sensitive adhesives for tapes and labels. In: Handbook of Adhesives. Springer, pp 641-663

[15] Gehman D. R. (1990) Acrylic adhesives. In: Handbook of Adhesives. Springer, pp 437-450

[16] Goulding T. (2003) Epoxy resin adhesives. In: Pizzi A, Mittal K (eds) Handbook of adhesive technology. pp 823-838

[17] Cranley P. E. (1984) Isocyanatoethyl methacrylate: A latent crosslinker for coating adhesive resins. In: Adhesive Chemistry. Springer, pp 765-784

[18] Wypych G. (2004) Handbook of plasticizers. ChemTec Publishing,

[19] Dunky M. (2003) Adhesives in the wood industry. In: Pizzi A, Mittal K (eds) Handbook of adhesive technology. pp 887-957

[20] Earhart N., Patel A., Knobloch G. (2003) Thermal stabilization of adhesives. In: Pizzi A, Mittal K (eds) Handbook of adhesive technology, . pp 441-455

[21] Malysheva G., Bodrykh N. (2011) Hot-melt adhesives. Polymer Science Series D 4 (4):301-303

[22] Gent A., Hamed G. (1990) Fundamentals of adhesion. In: Handbook of Adhesives. Springer, pp 39-73

[23] McBain J., Hopkins D. (1925) On adhesives and adhesive action. The Journal of Physical Chemistry 29 (2):188-204 
[24] Schultz J., Nardin M. (2003) Theories and mechanisms of adhesion. In: Pizzi A, Mittal K (eds) Handbook of adhesive technology. pp 53-67

[25] Cassidy P. E., Johnson J. M., Rolls G. C. (1972) Coupling Agents for Adhesive Systems. Industrial \& Engineering Chemistry Product Research and Development 11 (2):170-177

[26] Voyutskii S. S., Vakula V. L. (1963) The role of diffusion phenomena in polymer-topolymer adhesion. Journal of Applied Polymer Science 7 (2):475-491. doi:10.1002/app.1963.070070207

[27] De Bruyne N. A. (1957) Klebtechnik: die Adhäsion in Theorie und Praxis. Berliner Union

[28] Geminger T., Jarka S. (2016) Injection Molding of Multimaterial Systems. In: Specialized Injection Molding Techniques. Elsevier, pp 165-210

[29] Sharpe L., Schonhorn H. (1963) Theory gives direction to adhesion work. Chemical and engineering news 41 (15):67-68

[30] Le Bon A.-M., Datiche F., Gascuel J., Grosmaitre X. (2017) Olfactory system in mammals: structural and functional anatomy. In: Guichard E, Salles C, Morzel M, Le Bon A-M (eds) Flavour: From Food to Perception. pp 1-33

[31] Moran D. T., Rowley J. C., Jafek B. W., Lovell M. A. (1982) The fine structure of the olfactory mucosa in man. Journal of neurocytology 11 (5):721-746

[32] Morrison E. E., Costanzo R. M. (1992) Morphology of olfactory epithelium in humans and other vertebrates. Microscopy research and technique 23 (1):49-61

[33] Mackay-Sim A., Kittel P. (1991) Cell dynamics in the adult mouse olfactory epithelium: a quantitative autoradiographic study. Journal of Neuroscience 11 (4):979984

[34] Heydel J. M., Coelho A., Thiebaud N., Legendre A., Bon A. M. L., Faure P., Neiers F., Artur Y., Golebiowski J., Briand L. (2013) Odorant-binding proteins and xenobiotic metabolizing enzymes: implications in olfactory perireceptor events. The Anatomical Record 296 (9):1333-1345

[35] Vidic J., Grosclaude J., Monnerie R., Persuy M.-A., Badonnel K., Baly C., Caillol M., Briand L., Salesse R., Pajot-Augy E. (2008) On a chip demonstration of a functional role for odorant binding protein in the preservation of olfactory receptor activity at high odorant concentration. Lab on a Chip 8 (5):678-688

[36] Strotmann J., Breer H. (2011) Internalization of odorant-binding proteins into the mouse olfactory epithelium. Histochemistry and cell biology 136 (3):357

[37] Schilling B. (2017) Nasal Periceptor Processes. In: Buettner A (ed) Springer Handbook of Odor. Springer International Publishing, Cham, pp 605-616. doi:10.1007/978-3-319-26932-0_28

[38] Matsui A., Go Y., Niimura Y. (2010) Degeneration of olfactory receptor gene repertories in primates: no direct link to full trichromatic vision. Molecular biology and evolution 27 (5):1192-1200

[39] Kleene S. J. (2008) The electrochemical basis of odor transduction in vertebrate olfactory cilia. Chemical Senses 33 (9):839-859

[40] Kotthoff M. (2015) Odor and nutrition. Part 1: Fundamentals of smelling. Ernahrungs Umschau 62 (5):82-91

[41] Kajiya K., Inaki K., Tanaka M., Haga T., Kataoka H., Touhara K. (2001) Molecular bases of odor discrimination: reconstitution of olfactory receptors that recognize overlapping sets of odorants. Journal of Neuroscience 21 (16):6018-6025

[42] Malnic B., Hirono J., Sato T., Buck L. B. (1999) Combinatorial receptor codes for odors. Cell 96 (5):713-723

[43] Firestein S. (2001) How the olfactory system makes sense of scents. Nature 413 (6852):211 
[44] Heydel J.-M., Hanser H.-I., Faure P., Neiers F. (2017) Odorant metabolizing enzymes in the peripheral olfactory process. In: Guichard E, Salles C, Morzel M, Le Bon A-M (eds) Flavour: From Food to Perception. pp 34-56

[45] Doty R., Kamath V. (2014) The influences of age on olfaction: a review. Frontiers in Psychology 5 (20). doi:10.3389/fpsyg.2014.00020

[46] Keller A., Hempstead M., Gomez I. A., Gilbert A. N., Vosshall L. B. (2012) An olfactory demography of a diverse metropolitan population. BMC Neuroscience 13 (1):122. doi:10.1186/1471-2202-13-122

[47] Gingras-Lessard F., Frasnelli J. (2017) Basic physiology of the intranasal trigeminal system. In: Guichard E, Salles C, Morzel M, Le Bon A-M (eds) Flavour: From Food to Perception.

[48] Doty R. L., Brugger W. E., Jurs P. C., Orndorff M. A., Snyder P. J., Lowry L. D. (1978) Intranasal trigeminal stimulation from odorous volatiles: psychometric responses from anosmic and normal humans. Physiology \& Behavior 20 (2):175-185

[49] Bandell M., Story G. M., Hwang S. W., Viswanath V., Eid S. R., Petrus M. J., Earley T. J., Patapoutian A. (2004) Noxious cold ion channel TRPA1 is activated by pungent compounds and bradykinin. Neuron 41 (6):849-857

[50] Piggott J. R., Simpson S. J., Williams S. A. (1998) Sensory analysis. International journal of food science \& technology 33 (1):7-12

[51] Guadagni D. G., Buttery R. G., Okano S., Burr H. K. (1963) Additive Effect of SubThreshold Concentrations of Some Organic Compounds Associated with Food Aromas. Nature 200 (4913):1288-1289

[52] Laska M., Hudson R. (1991) A comparison of the detection thresholds of odour mixtures and their components. Chem Senses 16 (6):651-662

[53] Murray J., Delahunty C., Baxter I. (2001) Descriptive sensory analysis: past, present and future. Food research international 34 (6):461-471

[54] Stone H., Bleibaum R. N., Thomas H. A. (2012) Sensory evaluation practices. Academic press,

[55] McBride R. L. (1986) Hedonic rating of food: single or side-by-side sample presentation? International journal of food science \& technology 21 (3):355-363. doi:10.1111/j.1365-2621.1986.tb00414.x

[56] Belitz H.-D., Grosch W., Schieberle P. (2004) Aroma compounds. In: Food chemistry. Springer, pp 342-408

[57] Parliment T. (2002) Solvent extraction and distillation techniques. In: Marsili R (ed) Flavor, fragrance, and odor analysis. CRC Press, pp 1-23

[58] Sides A., Robards K., Helliwell S. (2000) Developments in extraction techniques and their application to analysis of volatiles in foods. TrAC Trends in Analytical Chemistry 19 (5):322-329

[59] Zellner B. d. A., Dugo P., Dugo G., Mondello L. (2008) Gas chromatographyolfactometry in food flavour analysis. Journal of Chromatography a 1186 (1-2):123143

[60] Buettner A., Schieberle P. (2001) Evaluation of Key Aroma Compounds in HandSqueezed Grapefruit Juice (Citrus paradisi Macfayden) by Quantitation and Flavor Reconstitution Experiments. Journal of Agricultural and Food Chemistry 49 (3):13581363. doi:10.1021/jf001235x

[61] Demole E., Enggist P., Ohloff G. (1982) 1-p-Menthene-8-thiol: A powerful flavor impact constituent of grapefruit juice (Citrus parodisi MACFAYDEN). Helvetica Chimica Acta 65 (6):1785-1794. doi:10.1002/hlca.19820650614

[62] Belardi R. P., Pawliszyn J. B. (1989) The application of chemically modified fused silica fibers in the extraction of organics from water matrix samples and their rapid transfer to capillary columns. Water Quality Research Journal 24 (1):179-191 
[63] Arthur C. L., Pawliszyn J. (1990) Solid phase microextraction with thermal desorption using fused silica optical fibers. Analytical chemistry 62 (19):2145-2148

[64] Louch D., Motlagh S., Pawliszyn J. (1992) Dynamics of organic compound extraction from water using liquid-coated fused silica fibers. Analytical chemistry 64 (10):11871199

[65] Arthur C. L., Killam L. M., Buchholz K. D., Pawliszyn J., Berg J. R. (1992) Automation and optimization of solid-phase microextraction. Analytical chemistry 64 (17):1960-1966

[66] Yang X., Peppard T. (1994) Solid-phase microextraction for flavor analysis. Journal of Agricultural and Food Chemistry 42 (9):1925-1930

[67] Jeleń H. H., Majcher M., Dziadas M. (2012) Microextraction techniques in the analysis of food flavor compounds: A review. Analytica Chimica Acta 738:13-26

[68] Kataoka H., Lord H. L., Pawliszyn J. (2000) Applications of solid-phase microextraction in food analysis. Journal of Chromatography a 880 (1-2):35-62

[69] Wardencki W., Michulec M., Curyło J. (2004) A review of theoretical and practical aspects of solid-phase microextraction in food analysis. International journal of food science \& technology 39 (7):703-717

[70] Werkhoff P., Brennecke S., Bretschneider W., Bertram H.-J. (2002) Modern Methods for Isolating and Quantifying Volatile flavor and Fragrance Compounds. In: Marsili R (ed) Flavor, fragrance, and odor analysis. Marcel Dekker New York, pp 139-204

[71] Górecki T., Yu X., Pawliszyn J. (1999) Theory of analyte extraction by selected porous polymer SPME fibres. Analyst 124 (5):643-649

[72] Miller M. E., Stuart J. D. (1999) Comparison of gas-sampled and SPME-sampled static headspace for the determination of volatile flavor components. Analytical chemistry 71 (1):23-27

[73] Penton Z. E. (1997) Sample preparation for gas chromatography with solid-phase extraction and solid-phase microextraction. Advances in chromatography 37:205-236

[74] Baltussen E., Sandra P., David F., Cramers C. (1999) Stir bar sorptive extraction (SBSE), a novel extraction technique for aqueous samples: theory and principles. Journal of Microcolumn Separations 11 (10):737-747

[75] Nogueira J. (2012) Novel sorption-based methodologies for static microextraction analysis: a review on SBSE and related techniques. Analytica Chimica Acta 757:1-10

[76] Neng N., Silva A., Nogueira J. (2010) Adsorptive micro-extraction techniques-Novel analytical tools for trace levels of polar solutes in aqueous media. Journal of Chromatography a 1217 (47):7303-7310

[77] Prieto A., Basauri O., Rodil R., Usobiaga A., Fernández L., Etxebarria N., Zuloaga O. (2010) Stir-bar sorptive extraction: a view on method optimisation, novel applications, limitations and potential solutions. Journal of Chromatography a 1217 (16):2642-2666

[78] Grimm C. C., Lloyd S. W., Miller J. A., Spanier A. M. (2002) The analysis of food volatiles using direct thermal desorption. Flavor, fragrance and odor analysis:55-74

[79] Bart J. (2001) Direct solid sampling methods for gas chromatographic analysis of polymer/additive formulations. Polymer Testing 20 (7):729-740

[80] Sunesson A.-L., Nilsson C.-A., Andersson B., Carlson R. (1992) Thermal desorption cold trap-injection in high-resolution gas chromatography: multivariate optimization of experimental conditions. Journal of Chromatography a 623 (1):93-103

[81] Cavalli J.-F., Fernandez X., Lizzani-Cuvelier L., Loiseau A.-M. (2003) Comparison of static headspace, headspace solid phase microextraction, headspace sorptive extraction, and direct thermal desorption techniques on chemical composition of French olive oils. Journal of Agricultural and Food Chemistry 51 (26):7709-7716 
[82] Wampler T. P. (2002) Analysis of food volatiles using headspace-gas chromatographic techniques. In: Marsili R (ed) Flavor, Fragrance, and Odor Analysis. CRC Press, pp 25-54

[83] Steinhart H., Stephan A., Bücking M. (2000) Advances in flavor research. Journal of High Resolution Chromatography 23 (7-8):489-496

[84] Buttery R. G., Teranishi R. (1963) Measurement of fat autoxidation and browning aldehydes in food vapors by direct vapor injection gas-liquid chromatography. Journal of Agricultural and Food Chemistry 11 (6):504-507

[85] Ortega-Heras M., González-SanJosé M., Beltrán S. (2002) Aroma composition of wine studied by different extraction methods. Analytica Chimica Acta 458 (1):85-93

[86] RANKIN S. A., BODYFELT F. W. (1995) Solvent desorption dynamic headspace method for diacetyl and acetoin in buttermilk. Journal of Food Science 60 (6):12051207

[87] Valero E., Miranda E., Sanz J., Martinez-Castro I. (1997) Automatic thermal desorption in GC analysis of dairy product volatiles. Chromatographia 44 (1-2):59-64

[88] Engel W., Bahr W., Schieberle P. (1999) Solvent assisted flavour evaporation - a new and versatile technique for the careful and direct isolation of aroma compounds from complex food matrices. European Food Research and Technology 209 (3):237-241. doi:10.1007/s002170050486

[89] Bemelmans J. M. H. (1979) Review of isolation and concentration techniques. In: Land DG NH (ed) Progress in flavour research. Applied Science Publisher, London, pp 79-98

[90] Bauer P., Buettner A. (2018) Characterization of Odorous and Potentially Harmful Substances in Artists' Acrylic Paint. Frontiers in public health 6

[91] Czerny M., Buettner A. (2009) Odor-Active Compounds in Cardboard. Journal of Agricultural and Food Chemistry 57 (21):9979-9984. doi:10.1021/jf901435n

[92] Schreiner L., Bauer P., Buettner A. (2018) Resolving the smell of wood-identification of odour-active compounds in Scots pine (Pinus sylvestris L.). Scientific reports 8 (1):8294

[93] Schreiner L., Loos H. M., Buettner A. (2017) Identification of odorants in wood of Calocedrus decurrens (Torr.) Florin by aroma extract dilution analysis and twodimensional gas chromatography-mass spectrometry/olfactometry. Analytical and Bioanalytical Chemistry 409 (15):3719-3729. doi:10.1007/s00216-017-0314-x

[94] Strangl M., Fell T., Schlummer M., Maeurer A., Buettner A. (2017) Characterization of odorous contaminants in post-consumer plastic packaging waste using multidimensional gas chromatographic separation coupled with olfactometric resolution. Journal of Separation Science 40 (7):1500-1507

[95] Strangl M., Schlummer M., Maeurer A., Buettner A. (2018) Comparison of the odorant composition of post-consumer high-density polyethylene waste with corresponding recycled and virgin pellets by combined instrumental and sensory analysis. Journal of Cleaner Production 181:599-607

[96] Tyapkova O., Czerny M., Buettner A. (2009) Characterisation of flavour compounds formed by $\gamma$-irradiation of polypropylene. Polymer Degradation and Stability 94 (5):757-769. doi:http://dx.doi.org/10.1016/j.polymdegradstab.2009.02.006

[97] Wiedmer C., Velasco-Schön C., Buettner A. (2017) Characterization of off-odours and potentially harmful substances in a fancy dress accessory handbag for children. Scientific reports 7 (1):1807

[98] Wiedmer C., Velasco-Schön C., Buettner A. (2017) Characterization of odorants in inflatable aquatic toys and swimming learning devices-which substances are causative for the characteristic odor and potentially harmful? Analytical and Bioanalytical Chemistry 409 (16):3905-3916 
[99] Nickerson G. B., Likens S. (1966) Gas chromatography evidence for the occurrence of hop oil components in beer. Journal of Chromatography a 21:1-5

[100] Chaintreau A. (2001) Simultaneous distillation-extraction: from birth to maturityreview. Flavour and Fragrance Journal 16 (2):136-148. doi:10.1002/ffj.967

[101] Augusto F., e Lopes A. L., Zini C. A. (2003) Sampling and sample preparation for analysis of aromas and fragrances. TrAC Trends in Analytical Chemistry 22 (3):160169

[102] Farkaš P., Sadecka J., Kováč M., Siegmund B., Leitner E., Pfannhauser W. (1997) Key odourants of pressure-cooked hen meat. Food Chemistry 60 (4):617-621

[103] Stevenson R., Chen X., Mills O. (1996) Modern analyses and binding studies of flavour volatiles with particular reference to dairy protein products. Food research international 29 (3-4):265-290

[104] Peng F., Sheng L., Liu B., Tong H., Liu S. (2004) Comparison of different extraction methods: steam distillation, simultaneous distillation and extraction and headspace codistillation, used for the analysis of the volatile components in aged flue-cured tobacco leaves. Journal of Chromatography a 1040 (1):1-17

[105] Delahunty C. M., Eyres G., Dufour J.-P. (2006) Gas chromatography-olfactometry. Journal of Separation Science 29 (14):2107-2125. doi:doi:10.1002/jssc.200500509

[106] Fuller G. H., Steltenkamp R., Tisserand G. (1964) The gas chromatograph with human sensor: perfumer model. Annals of the New York Academy of Sciences 116 (2):711724

[107] Blank I. (2002) Gas chromatography-olfactometry in food aroma analysis. Flavor, Fragrance, and Odor Analysis:297-331

[108] van Ruth S. M., O'Connor C. H. (2001) Influence of assessors' qualities and analytical conditions on gas chromatography-olfactometry analysis. European Food Research and Technology 213 (1):77-82. doi:10.1007/s002170100360

[109] Chaintreau A. (2002) Quantitative Use of Gas Chromatography-Olfactometry: The GC-“SNIF" method. In: Marsili R (ed) Flavour, Fragrance, and Odor analyis. Marcel Dekker, New York, pp 333-348

[110] Acree T., Barnard J., Cunningham D. (1984) A procedure for the sensory analysis of gas chromatographic effluents. Food Chemistry 14 (4):273-286

[111] Acree T. E., Teranishi R. (1993) Flavor science: Sensible principles and techniques. American Chemical Society

[112] Grosch W. (1993) Detection of potent odorants in foods by aroma extract dilution analysis. Trends in Food Science \& Technology 4 (3):68-73. doi:http://dx.doi.org/10.1016/0924-2244(93)90187-F

[113] Grosch W. (2001) Evaluation of the Key Odorants of Foods by Dilution Experiments, Aroma Models and Omission. Chem Senses 26 (5):533-545. doi:10.1093/chemse/26.5.533

[114] Ullrich F., Grosch W. (1987) Identification of the most intense volatile flavour compounds formed during autoxidation of linoleic acid. Zeitschrift für LebensmittelUntersuchung und Forschung 184 (4):277-282. doi:10.1007/bf01027663

[115] McDaniel M., Miranda-Lopez R., Watson B., Micheals N., Libbey L. (1990) Flavor and off-flavors. Elsevier: Amsterdam:23-36

[116] Miranda-Lopez R., Libbey L. M., Watson B. T., McDaniel M. R. (1992) Odor analysis of Pinot Noir wines from grapes of different maturities by a gas chromatographyolfactometry technique (Osme). Journal of Food Science 57 (4):985-993

[117] Linssen J., Janssens J., Roozen J., Posthumus M. (1993) Combined gas chromatography and sniffing port analysis of volatile compounds of mineral water packed in polyethylene laminated packages. Food Chemistry 46 (4):367-371 
[118] Van Ruth S., Roozen J., Cozijnsen J. (1996) Gas chromatography/sniffing port analysis evaluated for aroma release from rehydrated French beans (Phaseolus vulgaris). Food Chemistry 56 (4):343-346

[119] van Ruth S. M., Roozen J. P. (1994) Gas chromatography/sniffing port analysis and sensory evaluation of commercially dried bell peppers (Capsicum annuum) after rehydration. Food Chemistry 51 (2):165-170

[120] Pollien P., Ott A., Montigon F., Baumgartner M., Muñoz-Box R., Chaintreau A. (1997) Hyphenated headspace-gas chromatography-sniffing technique: screening of impact odorants and quantitative aromagram comparisons. Journal of Agricultural and Food Chemistry 45 (7):2630-2637

[121] Molyneux R. J., Schieberle P. (2007) Compound identification: A journal of agricultural and food chemistry perspective. Journal of Agricultural and Food Chemistry 55 (12):4625-4629

[122] Kovàts E. (1958) Characterization of organic compounds by gas chromatography. Part 1. Retention indices of aliphatic halides, alcohols, aldehydes and ketones. Helvetica Chimica Acta 41 (7):1915-1932

[123] van Den Dool H., Dec. Kratz P. (1963) A generalization of the retention index system including linear temperature programmed gas-liquid partition chromatography. Journal of Chromatography a 11:463-471. doi:http://dx.doi.org/10.1016/S00219673(01)80947-X

[124] Grosch W. (1994) Determination of potent odourants in foods by aroma extract dilution analysis (AEDA) and calculation of odour activity values (OAVs). Flavour and Fragrance Journal 9 (4):147-158

[125] Preininger M., Grosch W. (1994) Evaluation of key odorants of the neutral volatiles of Emmentaler cheese by the calculation of odour activity values. LWT-Food Science and Technology 27 (3):237-244

[126] Schieberle P. (1995) New developments in methods for analysis of volatile flavor compounds and their precursors. In: Characterization of Food. Elsevier, pp 403-431

[127] Schieberle P., Grosch W. (1987) Quantitative analysis of aroma compounds in wheat and rye bread crusts using a stable isotope dilution assay. Journal of Agricultural and Food Chemistry 35 (2):252-257

[128] Harris R., Lacey M., Brown W., Allen M. (1987) Determination of 2-methoxy-3alkylpyrazines in wine by gas chromatography/mass spectrometry. Vitis 26 (4):201207

[129] Guth H., Grosch W. (1990) Deterioration of soya-bean oil: quantification of primary flavour compounds using a stable isotope dilution assay. Lebensmittel-Wissenschaft \& Technologie 23 (6):513-522 
List of publications and author contribution

- Philipp Denk, Andrea Buettner; Sensory characterization and identification of odorous constituents in acrylic adhesives; International Journal of Adhesion and Adhesives; 78(2017) 182-188; https://doi.org/10.1016/j.ijadhadh.2017.06.020

Philipp Denk carried out the practical work and interpreted the results. Philipp Denk and Andrea Buettner contributed to the manuscript. Andrea Buettner and Philipp Denk conceived and designed the study.

- Philipp Denk, Andrea Buettner; Identification and quantification of glue-like off-odors in elastic therapeutic tapes; Analytical and Bioanalytical Chemistry (2018) 410: 3395 3404; https://doi.org/10.1007/s00216-018-1046-2

Philipp Denk carried out the practical work and interpreted the results. Philipp Denk and Andrea Buettner contributed to the manuscript. Andrea Buettner and Philipp Denk conceived and designed the study.

- Philipp Denk, Eva Ortner, Andrea Buettner; Characterization of odorants in waxes for hot melt adhesives using sensory and instrumental analyses; International Journal of Adhesion and Adhesives 95(2019); https://doi.org/10.1016/j.ijadhadh.2019.102406

Philipp Denk carried out the practical work and interpreted the results together with Eva Ortner. Philipp Denk, Eva Ortner and Andrea Buettner contributed to the manuscript. Andrea Buettner, Eva Ortner and Philipp Denk conceived and designed the study.

- Patrick Bauer, Philipp Denk, Julia Maria Fuss, Katja Lorber, Eva Ortner, Andrea Buettner; Correlations between odour activity and structural modifications of acrylates; Analytical and Bioanalytical Chemistry (2019); https://doi.org/10.1007/s00216-019-01936-6

Julia Maria Fuss carried out the syntheses and the odor threshold determination. Philipp Denk and Patrick Bauer determined the odor qualities. Philipp Denk and Patrick Bauer interpreted the results. Philipp Denk, Patrick Bauer, Eva Ortner and Andrea Buettner contributed to the manuscript. Andrea Buettner and Katja Lorber conceived and designed the study. 


\title{
2. Sensory characterization and identification of odorous constituents in acrylic adhesives
}

\author{
Philipp Denk, Andrea Buettner \\ International Journal of Adhesion and Adhesives 78(2017) 182-188
}

https://doi.org/10.1016/j.ijadhadh.2017.06.020

Author contribution:

Philipp Denk carried out the practical work and interpreted the results. Philipp Denk and Andrea Buettner contributed to the manuscript. Andrea Buettner and Philipp Denk conceived and designed the study.

Reprinted from International Journal of Adhesion and Adhesives 78, Philipp Denk, Andrea Buettner, Sensory characterization and identification of odorous constituents in acrylic adhesives, 182-188, Copyright (2017), with permission from Elsevier 


\title{
3. Identification and quantification of glue-like off-odors in elastic therapeutic tapes
}

\author{
Philipp Denk, Andrea Buettner
}

Analytical and Bioanalytical Chemistry (2018) 410: 3395-3404

https://doi.org/10.1007/s00216-018-1046-2

Author contribution:

Philipp Denk carried out the practical work and interpreted the results. Philipp Denk and Andrea Buettner contributed to the manuscript. Andrea Buettner and Philipp Denk conceived and designed the study.

Reprinted as the accepted version of the manuscript by permission from Springer-Verlag GmbH Germany, part of Springer Nature, Analytical and Bioanalytical Chemistry, Identification and quantification of glue-like off-odors in elastic therapeutic tapes, Philipp Denk, Andrea Buettner, Copyright (2018) 


\title{
4. Characterization of odorants in waxes for hot melt adhesives using sensory and instrumental analyses
}

\author{
Philipp Denk, Eva Ornter, Andrea Buettner \\ International Journal of Adhesion and Adhesives 95(2019) \\ https://doi.org/10.1016/j.ijadhadh.2019.102406
}

Author contribution:

Philipp Denk carried out the practical work and interpreted the results together with Eva Ortner. Philipp Denk, Eva Ortner and Andrea Buettner contributed to the manuscript. Andrea Buettner, Eva Ortner and Philipp Denk conceived and designed the study.

Reprinted from International Journal of Adhesion and Adhesives, 95, Philipp Denk, Eva Ortner, Andrea Buettner, Characterization of odorants in waxes for hot melt adhesives using sensory and instrumental analyses, Copyright (2019), with permission from Elsevier 


\section{Correlations between odour activity and structural modifications of acrylates}

Patrick Bauer, Philipp Denk, Julia Maria Fuss, Katja Lorber, Eva Ortner, Andrea Buettner Analytical and Bioanalytical Chemistry (2019) https://doi.org/10.1007/s00216-019-01936-6

Author Contribution:

Julia Maria Fuss carried out the syntheses and the odor threshold determination. Philipp Denk and Patrick Bauer determined the odor qualities. Philipp Denk and Patrick Bauer interpreted the results. Philipp Denk, Patrick Bauer, Eva Ortner and Andrea Buettner contributed to the manuscript. Andrea Buettner and Katja Lorber conceived and designed the study.

Reprinted as the accepted version of the manuscript by permission from Springer-Verlag GmbH Germany, part of Springer Nature, Analytical and Bioanalytical Chemistry, Correlations between odour activity and structural modifications of acrylates, Patrick Bauer, Philipp Denk, Julia Maria Fuss, Katja Lorber, Eva Ortner, Andrea Buettner, Copyright (2019) 